\title{
Horticultural and Pathological Aspects of Fusarium Wilt Management Using Grafted Melons
}

\author{
R. Cohen, C. Horev, Y. Burger, and S. Shriber \\ Department of Vegetable Crops, Agricultural Research Organization, Newe \\ Ya' ar Research Center, P.O. Box 1021, Ramat Yishay 30-095, Israel
}

\section{J. Hershenhorn}

Department of Weed Research, Agricultural Research Organization, Newe Ya' ar Research Center, P.O. Box 1021, Ramat Yishay 30-095, Israel

\section{J. Katan}

Department of Plant Pathology and Microbiology, Faculty of Agricultural, Food and Environmental Quality Science, Hebrew University, Rehovot 76 100 Israel

\section{Edelstein \\ Department of Vegetable Crops, Agricultural Research Organization, Newe Ya' ar Research Center, P.O. Box 1021, Ramat Yishay 30-095, Israel \\ Additional index words. soilborne pathogens, Cucumis melo, Cucurbita, rootstock, F. oxysporum f. sp. melonis}

\begin{abstract}
The effect of Cucurbita and melon rootstocks on the horticultural and pathological performance of grafted Fusarium-susceptible melons was studied in four field experiments conducted in Fusarium-infested and Fusarium-free soils. The melon/melon combinations performed better than the melon/Cucurbita combinations regarding yield and disease control. In the 1999 experiment conducted in infested soil, Fusarium wilt symptoms were observed only in the nongrafted susceptible melons whereas all grafted combinations were symptom-free. In the 2000 experiment, nongrafted susceptible melons were totally wilted, whereas disease incidence in the melon/melon combinations and in one of the melon/Cucurbita combinations was low. The response of grafted plants to Fusarium wilt was also affected by the susceptibility of the scion. Among nongrafted melon cv. Ananas Ein Dor and those grafted onto Brava rootstock, $82 \%$ and $20 \%$, were diseased, respectively, compared with only $36 \%$ and $0 \%$, of the nongrafted and grafted 'Ofir' melons, respectively. Negligible quantities of fruit were harvested from the nongrafted plants grown in infested soil, whereas high and moderate yields were obtained from melons grafted onto melon and Cucurbita rootstocks, respectively. The yield of the nongrafted melons in Fusarium-free soils were similar to those of all the grafted plant combinations. Susceptible melon scions grafted onto resistant melon rootstocks were less colonized by $F$. oxysporum f. sp. melonis than the same melons grafted onto the Cucurbita rootstocks.
\end{abstract}

Fusarium wilt of melons (Cucumis melo L.) is a worldwide problem. Disease symptoms can be observed at all developmental stages of the plant, but mostly at the fruit ripening stage (Martyn and Gordon, 1996). The use of resistant cultivars is the most effective and practical means for controlling the disease. Since four races of the pathogen $(0,1$, 2 , and 1,2 ), are known worldwide, including in Israel (Cohen et al., 1989; Martyn and Gordon, 1996; Mas et al., 1981), it is necessary to determine the race composition present in a given area before a cultivar is chosen (Martyn and Gordon, 1996). In Israel, Fusarium wilt of melons is an important disease in Ananas-type melons grown in the summer under dry-land

Received for publication 27 Aug. 2001. Accepted for publication $26 \mathrm{Feb}$. 2002. Contribution from the Agricultural Research Organization. The Volcani Center, Bet Dagan, Israel. No 117/2001. farming conditions. Fusarium-resistant Ananas-type cultivars do exist, but their fruit quality is lower than that of the susceptible cv. Ofir, the leading commercial Ananas type. Grafting high-fruit quality but susceptible cultivars onto resistant rootstocks is one of the approaches that enables such melon cultivars to be grown in infested soils (Traka-Mavrona et al., 2000).

Grafting vegetables, including cucurbits, is a common practice in Japan, Korea, the Mediterranean Basin and some countries in Europe. Melons are grafted mainly to control Fusarium wilt (Lee, 1994; Morra, 1998; TrakaMavrona et al., 2000). In addition to disease control, grafted plants may also have better tolerance of environmental stresses such as saline soil and low soil temperatures (Lee, 1994). Grafting has the potential to prevent other diseases. In field trials conducted in the Arava region of southern Israel, the incidence of Monosporascus wilt on grafted melon plants was significantly lower than that on nongrafted plants (Edelstein et al., 1999).

The use of grafted cucurbits in Israel was insignificant because of the availability of methyl bromide for soil disinfestations. This situation is rapidly changing because of the impending ban on methyl bromide usage (Klein, 1996; Ristaino and Thomas, 1997; Shishido et al., 1992).

The results of grafting melons onto Cucurbita L. rootstocks, in our previous studies (Edelstein et al., 1999) and elsewhere (Traka-Mavrona et al., 2000), have been varied. In addition to the response to the disease, the performance of the grafted plant depends on the rootstocks' compatibility with the scions, the environmental conditions, and cultivation methods (Lee, 1994). In some cases, the rootstock's vigorous root system enables grafted plants to absorb water and nutrients more efficiently than nongrafted plants, and may also serve as a supplier of endogenous plant hormones. Thus, rootstock performance may lead to yield increases in addition to disease control (Cook and Baker, 1983; Lee, 1994). On the other hand, poor rootstockscion compatibility may lead to yield reduction, poor fruit quality, and even plant collapse (Lee, 1994; Traka-Mavrona et al., 2000). Negative side-effects that were exhibited in some of the melon/Cucurbita combinations (TrakaMavrona et al., 2000) stimulated the use of Fusarium-resistant melons as rootstocks (Cohen et al., 2000; Nerson et al., 1989). Preliminary results indicated that the yields of melons grafted onto Cucurbita rootstocks, grown in fields naturally infested with Fusarium, were low as compared with those of nongrafted resistant melon cultivars (R. Cohen, unpublished).

The objectives of the present study were to investigate the horticultural performance and the response to Fusarium wilt of various combinations of susceptible melons of the Ananas type grafted onto Cucurbita (usually interspecific $\mathrm{F}_{1}$ hybrids, Cucurbita maxima Duchesne $x$ Cucurbita moschata Duchesne) and melon rootstocks, under dry land farming field conditions.

\section{Materials and Methods}

Grafting melon plants on Cucurbita and melon rootstocks. The grafting procedure was as described by Lee (1994). Seeds of melon (Cucumis melo L.) and Cucurbita were sown in seedlings trays (Polyvid, Mishmar HaNegev, Israel, $37 \mathrm{~mm} /$ cell, 128 cells/tray) filled with a mixture of 1 peat : 1 vermiculite $(\mathrm{v} / \mathrm{v})$. The plants were grown in an environment-controlled greenhouse at $25{ }^{\circ} \mathrm{C}$ day $/ 20^{\circ} \mathrm{C}$ night and grafted at the two-leaf stage. The true leaves of the rootstocks were removed with a razor blade, creating a V-shaped cut between the cotyledons. An inverse V-shaped cut was made on the stem of the scion, $\approx 2 \mathrm{~cm}$ below the cotyledons, to fit the cut in the rootstock. Scion and rootstock were held with a grafting clip (Sakata Seed Corp., Yokohama, Japan). Grafted plants were transferred to a mist chamber [relative humidity $(\mathrm{RH})>95 \%$ ] for $8 \mathrm{~d}$, and 
then the RH was reduced gradually for acclimatization (Lee, 1994).

Effect of the rootstock on disease incidence of the grafted plant. The performance of melons grafted onto Cucurbita and melon rootstocks was evaluated in four field experiments. Two experiments were conducted in naturally Fusarium-infested soil in Bet Netuofa Valley and two in Fusarium-free soil in Newe Ya'ar, both in northern Israel. The two locations are $10 \mathrm{~km}$ apart and they have the same soil type and climate. In all four experiments, the Fusarium-susceptible melon cv. Ofir (Ananas type, Zeraim, Gedera, Israel) served as the scion. The experiments compared three grafted combinations: 1) 'Ofir' melons grafted onto the Cucurbita rootstock TZ-148 (Tezir, France); 2) 'Ofir' melons grafted onto the Fusarium-resistant melon Adir (Ananas type, Zeraim, Gedera, Israel); and 3) 'Ofir' melons grafted onto the Fusarium-resistant melon, Orca (Charentais type, Tezir, France). Nongrafted 'Ofir' melons were used as controls. In the experiments conducted in the 2000 cropping season, 'Ofir' was also grafted onto Brava (Cucurbita maxima rootstock, Petoseed, Spain). The two melon rootstocks are resistant to races 0,1 , and 2 of Fusarium oxysporum $\mathrm{f}$. sp. melonis, and are highly tolerant to races 1 , 2 of the pathogen. The two experiments conducted in the infested soils were transplanted on 4 Apr. 1999 and 12 Apr. 2000 (spring cropping). The first experiment in the Fusarium-free soil, conducted in late summer, was transplanted on 19 Aug. 1999 and the second, in the spring, was transplanted on 10 Apr. 2000. Each experiment plot treatment consisted of one bed, $15 \mathrm{~m}$ long containing 30 plants. The inter-row spacing in all experiments was $50 \mathrm{~cm}$ and beds were $190 \mathrm{~cm}$ apart. There were four replicates per treatment in the four field experiments. Each plant was manually irrigated with $1 \mathrm{~L}$ of water at transplanting time. The plants were grown without further irrigation (dry-land farming), using the available water in the soil.

Effect of the scion susceptibility on disease incidence of the grafted plant. The experiment consisted of four treatments. 'Ananas Ein Dor' and 'Ofir' (Zeraim, Gedera, Israel), both susceptible to all races of Fusarium oxysporum $\mathrm{f}$. sp. melonis, were grafted onto the Cucurbita rootstock Brava and were compared with nongrafted plants of the above cultivars. The experiment was transplanted on 29 Mar. 1998 in soil naturally infested with $F$. oxysporum $\mathrm{f}$. sp. melonis, in Bet Netuofa Valley in northern Israel. Each experiment plot consisted of one bed, $15 \mathrm{~m}$ long, containing 30 plants. The inter-row spacing in all experiments was 50 $\mathrm{cm}$ and beds were $190 \mathrm{~cm}$ apart. There were four replicates per treatment.

Disease evaluation and fruit quality measurement. Plants affected by Fusarium wilt were evaluated visually. A plant was considered dead when it appeared irreversibly wilted. The presence of $F$. oxysporum $\mathrm{f}$. sp. melonis in the wilting plants was confirmed by isolating the pathogen from their stems and melon seedlings were inoculated with these isolates, in order to determine the pathogen race, as described previously (Cohen et al., 1989). The number of wilted plants and the total number of plants per plot were used to calculate wilt incidence. Upon ripening, the fruits from each plot were counted and weighed. The fruits were sorted according to their peel-netting index; an index of $0-5$, based on a combination of coverage percentage and net thickness, which is considered to denote high-quality melons (Nerson et al., 1989). Total soluble solids (TSS) were evaluated from a sample of five high-quality fruits per plot, by means of a digital refractometer (Atago Co., Tokyo, Japan).

Colonization of scion stems by $F$. oxysporum f. sp. melonis. In the 1999 and 2000 experiments conducted in the Fusarium-infested soil, stem sections ( $5 \mathrm{~mm}$ thick) were sampled from the melon scions at 10,20, and $30 \mathrm{~cm}$ above the grafting site, $53 \mathrm{~d}$ after transplanting. The stem sections were plated on a Fusarium-selective medium (Alon et al., 1974) and were incubated for $5 \mathrm{~d}$ at $27{ }^{\circ} \mathrm{C}$. Each value presented in Fig. 6 is the average of 20 stem sections (five sections per stem height for four plants per rootstock).

Statistical analysis. Results of yield and disease incidence were statistically analyzed with the Student-Newman-Keuls multiple range test, applied with Super Anova software on a Macintosh computer. The disease incidence data were arcsin transformed prior to analysis.

\section{Results}

Response of grafted plants to Fusarium wilt-Effect of the rootstock. In the 1999 experiment conducted in infested soil, first Fusarium wilt symptoms were observed only in the nongrafted melons, $38 \mathrm{~d}$ after planting; all plants in this treatment collapsed by the end of the experiment. No wilting was observed in the plants grafted on the melon and the Cucurbita rootstocks. However, suppressed growth and some wilting of old vines were observed in melons grafted onto the Cucurbita rootstock TZ-148, whereas melons grafted onto melon rootstocks exhibited normal growth (Fig. 1). In the experiment conducted in spring 2000 , disease was first observed in the nongrafted plants 49 d after transplanting, whereas melons grafted onto Cucurbita rootstocks exhibited first wilt symptoms $74 \mathrm{~d}$ after planting (Fig 2). Disease incidence of the grafted plants was significantly lower as compared with the nongrafted melons until $82 \mathrm{~d}$ after planting. At the last observation, $89 \mathrm{~d}$ after planting, $94 \%$ of the nongrafted plants were dead, compared with $37 \%$ and $60 \%$ in the 'Ofir 'plants grafted on the Cucurbita TZ-148 and Brava rootstocks, respectively, and with $10 \%$ and $15 \%$ in 'Ofir' plants grafted on the resistant melon Orca and Adir rootstocks, respectively (Fig. 2).

Response of grafted plants to Fusarium wilt-Effect of the scion. The response of grafted plants was affected by the susceptibility of the scion. By $78 \mathrm{~d}$ after planting, $82 \%$ of the nongrafted 'Ananas Ein Dor' melons had wilted compared with only $36 \%$ of the nongrafted 'Ofir' melons (Fig. 3). The same gradation of susceptibility was evident in the grafted plants. 'Ananas Ein Dor' melons grafted onto Brava rootstock exhibited $20 \%$ mortality by the end of the experiment, whereas 'Ofir' grafted on the same rootstock did not show any wilting symptoms (Fig. 3).

Effect of grafting on yield components and fruit quality. In the 1999 experiment conducted in infested soil, negligible fruit quantities were harvested from the control treatment (nongrafted 'Ofir' plants). There were significant differences in yield among the three scion/ rootstock combinations: 'Ofir' grafted onto Adir melon rootstock yielded $21 \mathrm{~kg} / 10 \mathrm{~m}^{2}$, onto Orca melon rootstock $15.8 \mathrm{~kg} / 10 \mathrm{~m}^{2}$, and onto the Cucurbita rootstock, TZ-148, only $11.8 \mathrm{~kg} / 10 \mathrm{~m}^{2}$ (Fig 4A). The melon qualities were positively correlated with the quantities; the percentages of the total yield that comprised high-quality fruits with a net index of 4 5 were $93 \%, 79 \%, 56 \%$, and $33 \%$, for melons grafted onto Adir, Orca, and TZ 148 rootstocks, and for nongrafted melons, respectively. However, there were no significant differences among the yields of melons grafted onto different rootstocks in the experiment conducted during the 2000 crop season in the Fusariuminfested soil (Fig 4B). However, the trend observed in the 1999 experiment, with melons grafted on melon rootstocks having higher yields, was also evident in the 2000 experiment. In the experiments in Fusarium-infested soil, fruit maturation was somewhat earlier in melons grafted onto Cucurbita rootstocks than in those on melon rootstocks. For example, in the 1999 experiment $81 \%$ of the total yield of melons grafted onto TZ-148 was harvested by the second harvest, as compared with $28 \%$ of the melons grafted onto Adir (Fig 4A). The same trend of early maturation in the melons grafted onto Cucurbita rootstocks was also observed in the experiment conducted in spring 2000 (Fig. 4B).

No differences were observed in total yield and rate of fruit maturation, among all treatments tested in the Fusarium-free soil (nongrafted melons and melons grafted onto Cucurbita and melon rootstocks), in the two experiments conducted in the Fusarium-free soil (late Summer 1999, Fig. 5A and Spring 2000, Fig. 5B). The netting indexes of the fruits in all treatments were high, ranging from 4 to 5 , while TSS ranged between $11.2 \%$ and $12.3 \%$.

Colonization of scion stems by $F$. oxysporum f. sp. melonis. Melon scions (susceptible cv. Ofir) grafted onto Fusarium-resistant melon rootstocks and grown in the infested soil, were less colonized by $F$. oxysporum f. sp. melonis than melons grafted onto the Cucurbita rootstock TZ 148 or the nongrafted Ofir melons (Fig. 6). Colonization of stem sections of the melon/melon combinations at $10 \mathrm{~cm}$ above the grafting site ranged from $15 \%$ to $28 \%$ as compared with $73 \%$ to $98 \%$ in the melon/Cucurbita combinations and the nongrafted controls, respectively (Fig. 6). 


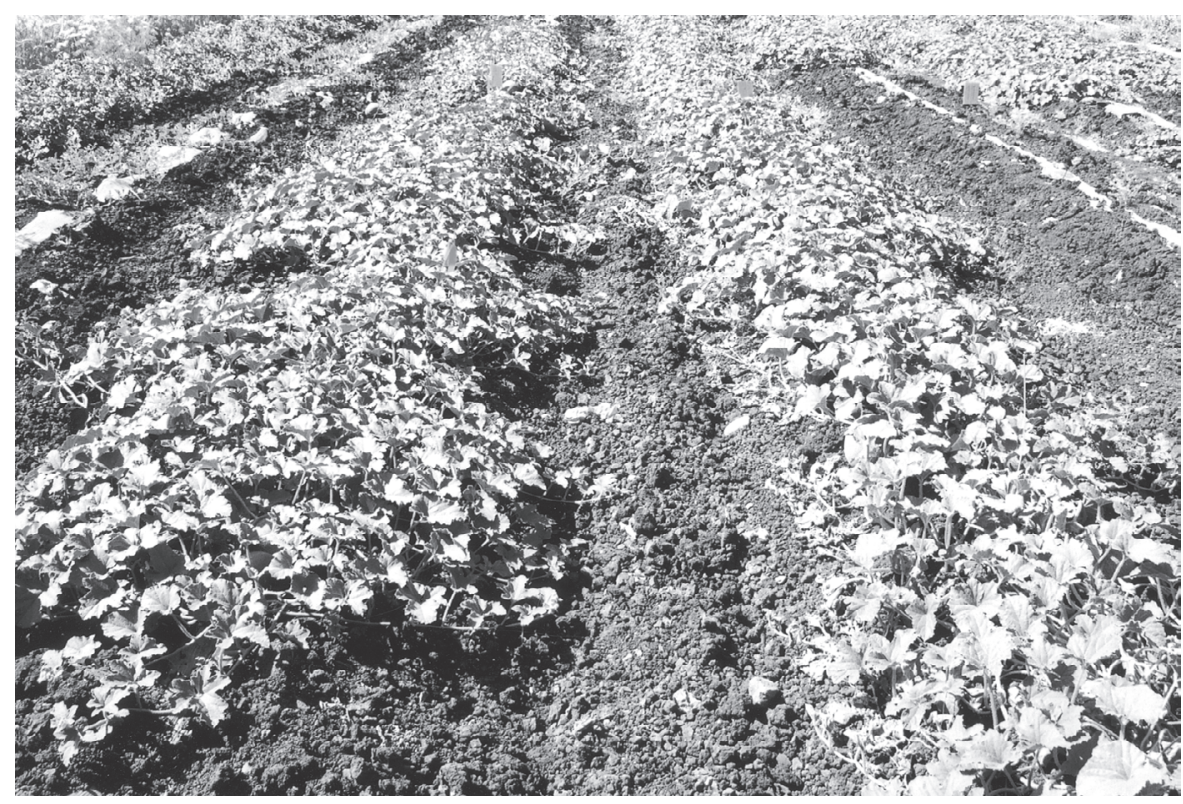

Fig. 1. Grafted melons (susceptible cv. Ofir), grown in naturally Fusarium-infested soil in Bet Netuofa Valley in spring 1999. Suppressed growth and some wilting of old vines of melons grafted onto the Cucurbita rootstock TZ-148, (right foreground) as compared with normal growth of melons grafted onto melon rootstocks (left foreground).

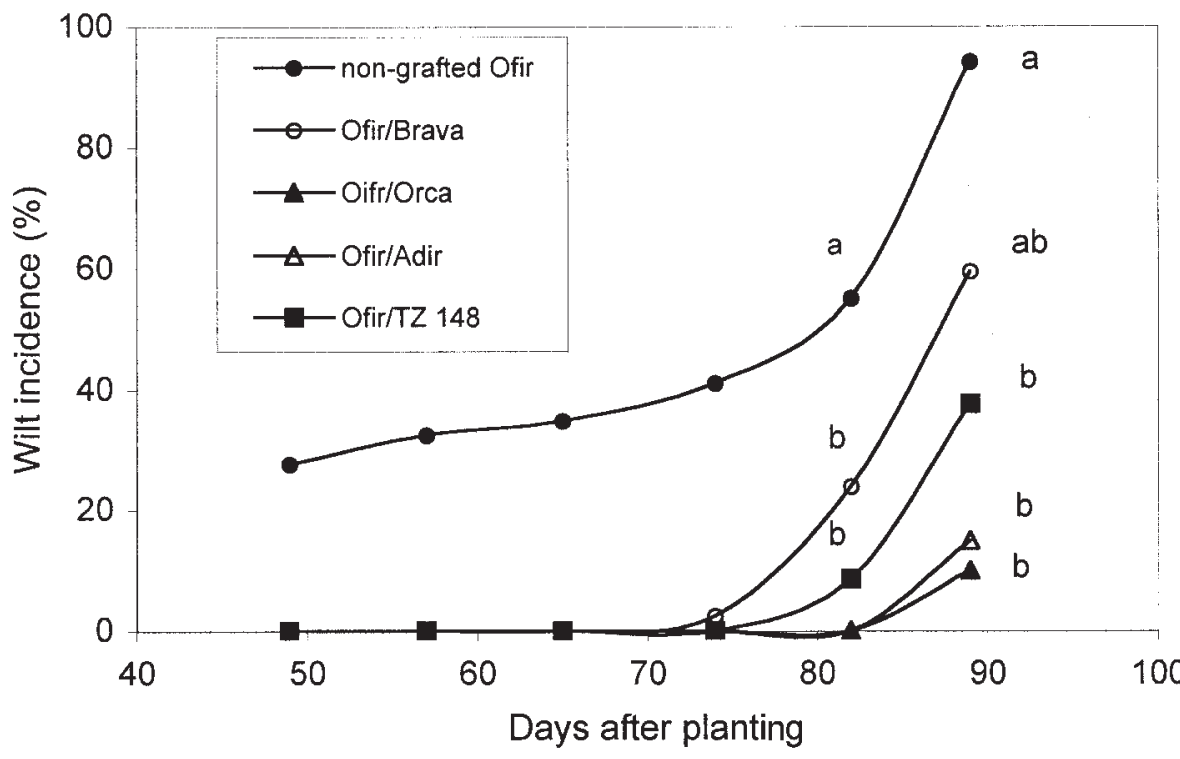

Fig. 2. Effect of the rootstock on Fusarium disease incidence of the grafted plant. Wilt incidence of 'Ofir' melons grafted and nongrafted, grown in Fusarium-infested soil. The experiment conducted in 1998. Values (dates after planting), followed by different letters are significantly different $(P \geq 0.05)$.

\section{Discussion}

Our study shows that grafting susceptible melon plants of the desired cultivar (e.g., 'Ofir') onto a suitable rootstock provides a high level of resistance to Fusarium wilt. Since disease incidence was reduced by $85 \%$ to $100 \%$ (Figs. 2 and 3 ), the yields of these grafted plants were similar to that obtained with nongrafted plants in a noninfested soil, in the experiments conducted in the spring (Figs. 4 and 5B).

The advantage of melon/melon overmelon/ Cucurbita combinations in yield and disease control was observed in the experiments conducted in infested soil. In the 1999 experiment, the nongrafted controls were totally wilted while no wilting was observed in any of the combinations of grafted plants. However, significantly lower yield quality and quantity were obtained from melons grafted onto the Cucurbita rootstock TZ 148 than from melons grafted onto a melon rootstock (Fig. 4). In this experiment, 'Ofir' gave a significantly higher yield when grafted onto Adir, probably because both are of the same Ananas type, than when grafted onto Orca, which is of a Charantais type. The vigor of the melon/ of the melon/melon combinations; some growth suppression and partial wilting of old Cucurbita combinations was lower than that vines were observed (Fig. 1). These differences were also reflected in yield but the differences were significant only in the 1999 experiment. Melons grafted onto Cucurbita produced fruit somewhat earlier than those grafted on melons. This may indicate a stress (Shishido et al., 1992) that stemmed from grafting incompatibility or, more likely, from a low level of disease.

The effect of grafting on the yield per se was tested in late Summer 1999 and in Spring 2000 in Fusarium-free soil. As dryland farming depends mostly on the available water remaining in the soil from winter rains, the yield in the spring (Fig. 5B), was higher than that in the late-summer experiment, which was planted in August under conditions of dryer soil and higher air temperatures (Fig. 5A). No differences among treatments (nongrafted and grafted melons), were evident in either of the experiments conducted in Fusarium-free soil, which further supports the hypothesis that the differences in yield are attributable to the disease (in the grafted plants), which was apparent in 2000 but concealed in the 1999 experiment.

Some studies have demonstrated that certain Cucurbita rootstocks may cause a remarkable deterioration in the taste of melons, indicating that the metabolites associated with fruit quality are translocated to the scion through the xylem (Lee, 1994; Traka-Mavrona et al., 2000). Our results (that depended mostly on TSS measurements and the peel netting index), however, showed that the quality of Ananas-type melons, grown under dry land farming conditions, in Fusarium-free soil, was not negatively affected by grafting. Hence, the decrease in quality of melons grafted onto Cucurbita rootstocks (Traka-Mavrona et al., 2000) was not an example of a general phenomenon but rather resulted from a particular scion/rootstock interaction, and a particular combination of growing conditions, including response to diseases.

There is a variety of mechanisms by which plants defend themselves from vascular pathogens. Biles et al. (1989) suggested that Fusarium-suppressing substances are synthesized in the roots and translocated to the stems through the xylem. Occlusion of the pathogen in the crown area and restriction of the colonization of the vascular system has been suggested as one but not the sole resistance mechanism (Beckman, 1987). Alon et al. (1974) found that resistance of tomato to Fusarium was correlated with a reduced rate of fungal colonization, especially in the upper parts of the plant. Grafting has also been used to study the pathogenesis process in tomatoes; it was shown that a resistant rootstock was invaded by the pathogen, whereas the susceptible scion was not colonized, but the resistant scion showed vascular browning and wilting, indicating a toxic reaction (Pegg, 1981). In melons, there is no complete occlusion of the pathogen in the lower part of the stem and the fungus does penetrate and colonize the stems of resistant plants, but to a lesser extent than in susceptible melons (Cohen et al., 1987). The relatively low colonization of the stem sec- 


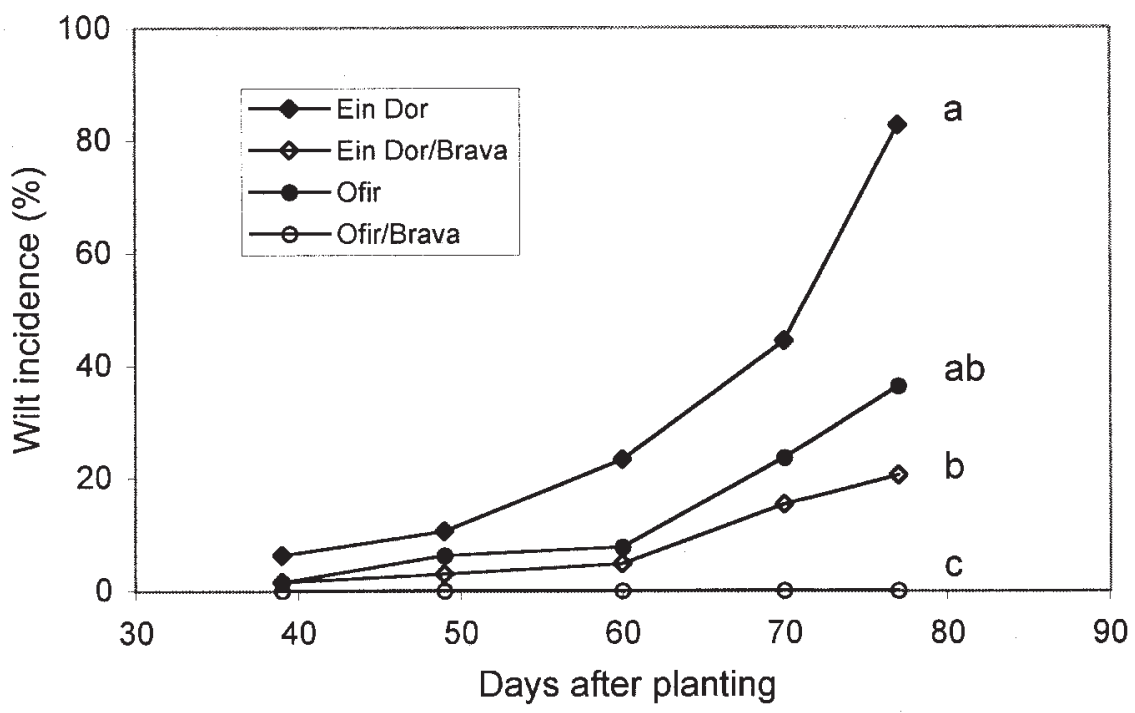

Fig. 3. Effect of the scion on Fusarium disease incidence of the grafted plant. Wilt incidence on nongrafted susceptible melon cultivars ('Ananas Ein Dor' and 'Ofir') and on the same cultivars grafted on the Cucurbita rootstock Brava. Final wilt incidence values followed by different letter are significantly different $(P \geq 0.05)$ The experiment were conducted at Bet Netuofa Valley, Spring 1999.
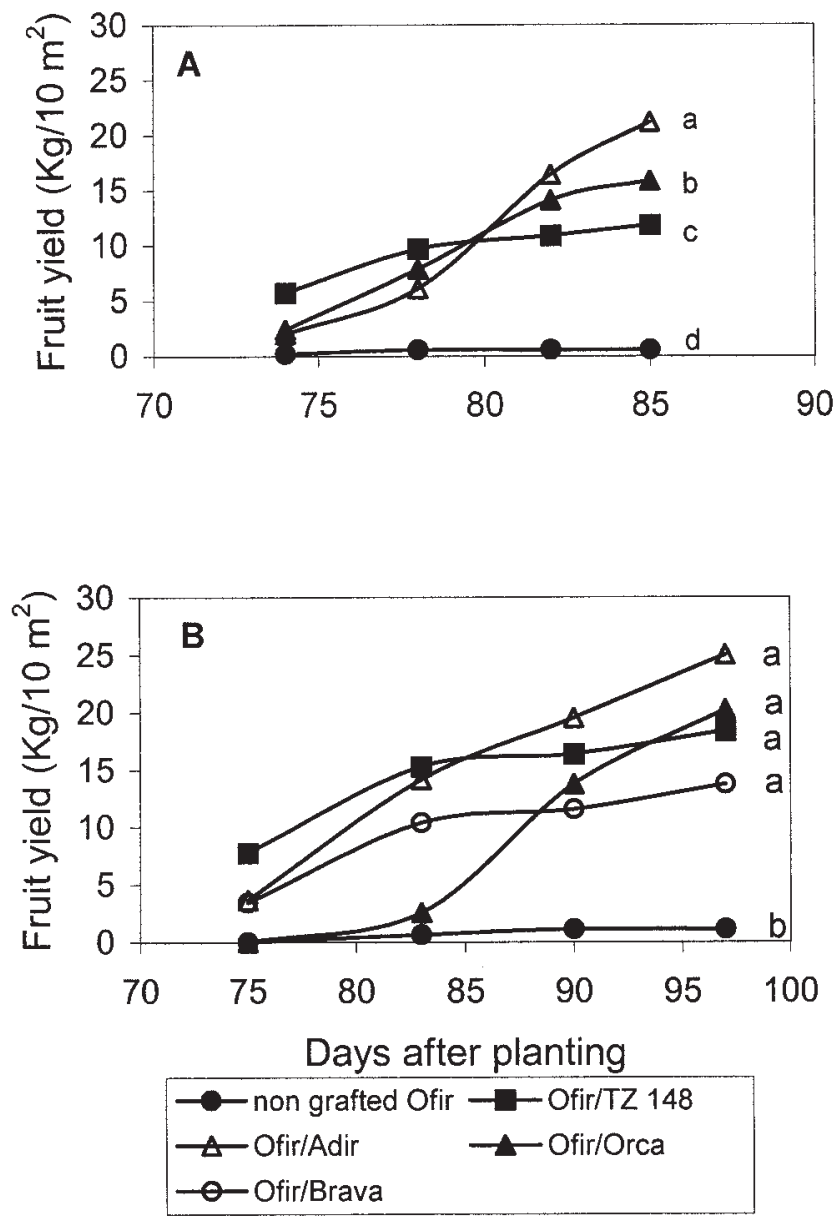

Fig. 4. Accumulated yield of grafted and nongrafted melons in the spring crops of the 1999 (A) and Spring 2000 (B) experiments, conducted in Fusarium-infested soil in Bet Netuofa Valley. Values followed by different letters are significantly different $(P \geq 0.05)$. tions above the grafting site, in the melon/ melon combination as compared with the nongrafted melons and the melon/Cucurbita combination, was apparently associated with a reduction in disease incidence. The $C$ ucurbita rootstocks provided only partial disease reduction; it seems that the effect of these rootstocks, in slowing down the penetration of the pathogen into the scion and probably inhibiting toxin production or activity, was only partial. The fact that the pathogen can penetrate the rootstock and pass the grafting site toward the scion makes the Cucurbita rootstocks only partially effective in protecting melons from Fusarium wilt. However, the Cucurbita rootstocks have been found highly effective against root rot and stem rot diseases such as Monosporascus wilt of melons (Edelstein et al., 1999) and charcoal rot (Macrophomina phaseolina) in watermelons (Cohen, unpublished).

Our present study indicates that the resistance level achieved by grafting depends also on the scion. Therefore, the grafting approach should take into consideration the responses of both the rootstock and the scion to the disease. Grafting is potentially an environmentally acceptable alternative to methyl bromide application, since a suitable combination of rootstock and scion can provide effective disease control and ensure a satisfactory yield.

\section{Literature Cited}

Alon, H., J. Katan, and N. Kedar. 1974. Factors affecting penetrance of resistance to Fusarium oxysporum f. sp. lycopersici in tomatoes. Phytopathology 64:455-461.

Beckman, C.H. 1987. The nature of wilt diseases of plants. APS Press, St. Paul, Minn.

Biles, C.L., R.D. Martyn, and H.D. Wilson. 1989. Isozymes and general proteins from various watermelon cultivars and tissue type. HortScience 24:810-812.

Cohen, R., O. Yarden, J. Riov, N. Lisker, and J. Katan. 1987. Paclobutrazol and other plant growth retardant chemicals increase resistance of melon seedlings to Fusarium wilt. Plant $\mathrm{Pa}$ thology 36:558-564.

Cohen, R., T. Katan, J. Katan, and Ruth Cohn. 1989. Occurrence of Fusarium oxysporum f. sp. melonis race 1,2 on muskmelon in Israel. Phytoparasitica 17:319-322.

Cohen, R., S. Pivonia, Y. Burger, M. Edelstein, A. Gamliel, and J. Katan. 2000. Toward integrated management of Monosporascus wilt of melons in Israel. Plant Dis. 84:496-505.

Cook, R.J. and K.F. Baker. 1983. The nature and practice of biological control of plant pathogens. Amer. Phytopathol. Soc., St. Paul, Minn.

Edelstein, M., R. Cohen, S. Shariber, S. Pivonia, and D. Shtienberg. 1999. Integrated management of sudden wilt in melons, caused by Monosporascus cannonballus, using grafting and reduced rates of methyl bromide. Plant Dis. 83:1142-1145.

Klein, L. 1996. Methyl bromide as soil fumigant, p. 191-235. In: C.H. Be, N. Price, and B. Chakrabarti (eds.). The methyl bromide issue. Wiley, New York.

Lee, J.M. 1994. Cultivation of grafted vegetables I. Current status, grafting methods, and benefits. HortScience 29:235-239.

Martyn, R.D. and T.R. Gordon. 1996. Fusarium wilt of melon. In: T.A. Zitter, D.L.Hopkins, and C.E. 

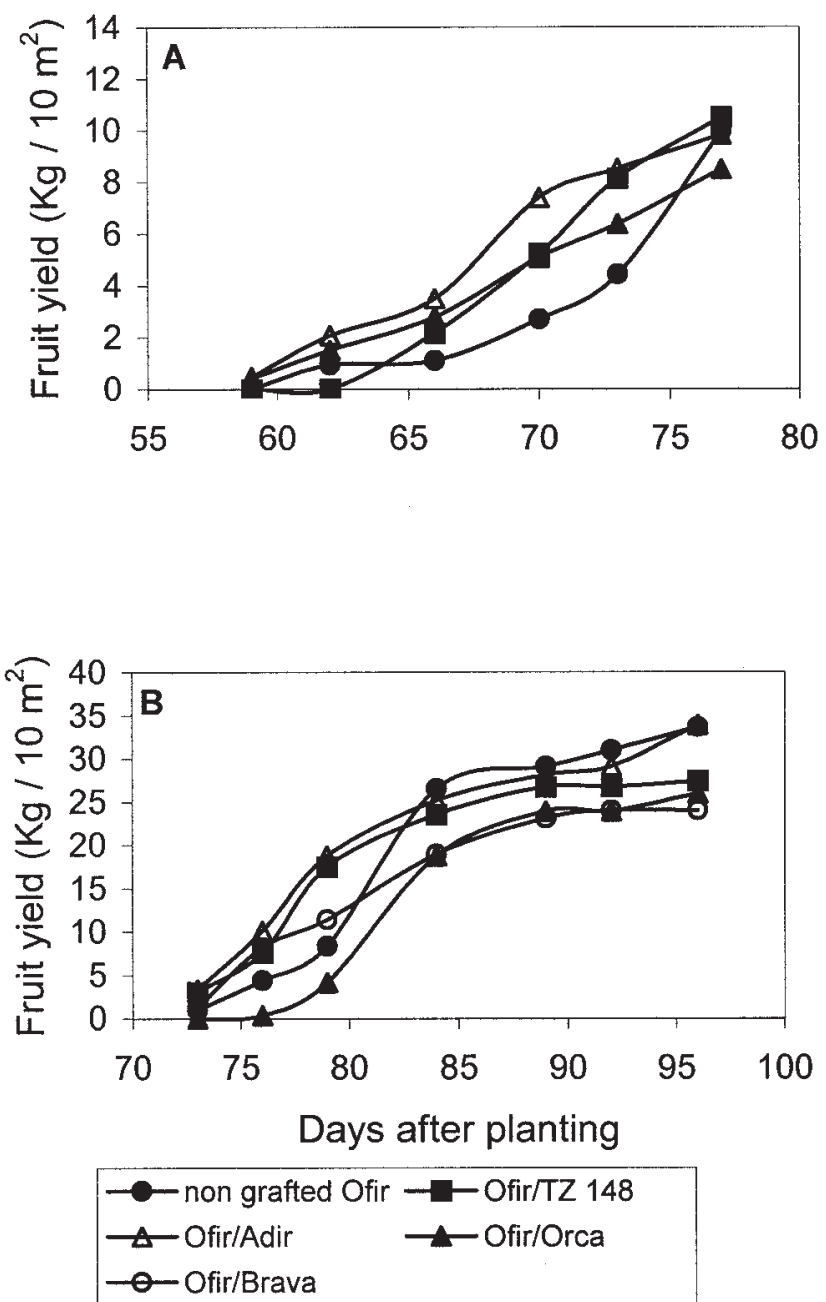

Fig. 5. Accumulated melon yields in Summer 1999 (A) and Spring 2000 (B) experiments conducted in Fusarium-free soil in Newe Ya'ar. No significant differences between treatments were observed in the two experiments.

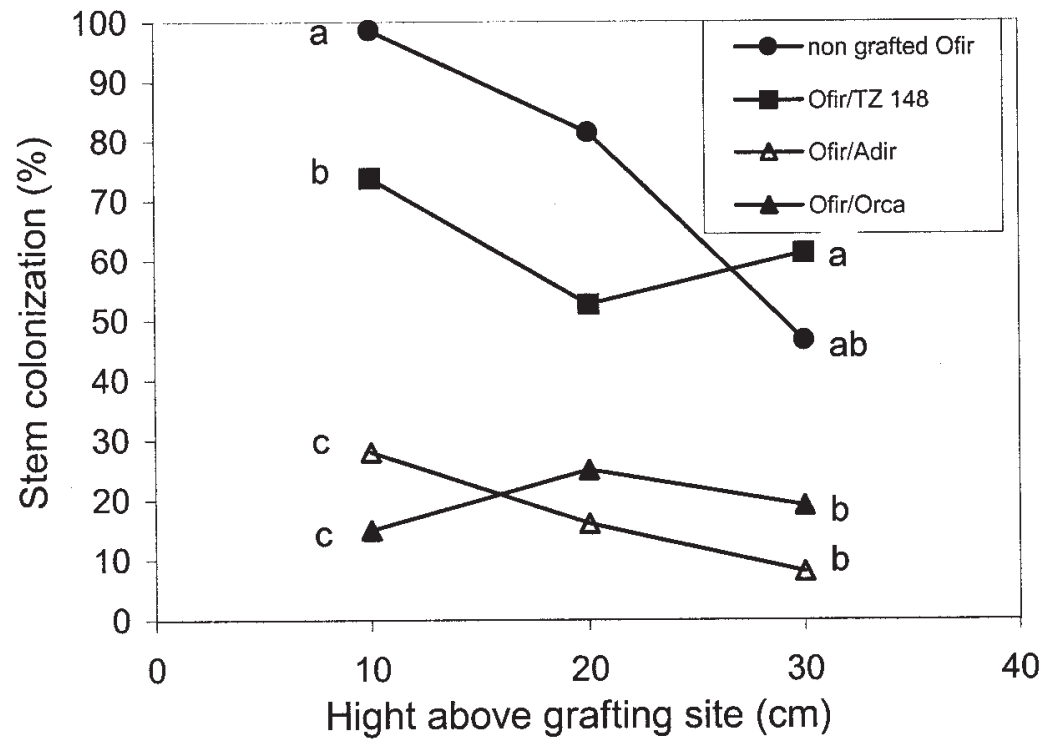

Fig. 6. Colonization of stem segments of grafted and nongrafted melons at different heights above the grafting site. Samples were taken from the 1999 experiment, $53 \mathrm{~d}$ after planting. Values followed by different letters, at each stem height, are significantly different $(P \geq 0.05)$.
Thomas (eds.). Compendium of cucurbit disease. APS Press, St. Paul, Minn.

Mas, P., P.M. Molot, and G. Risser. 1981. Fusarium wilt of muskmelon. In: P.E. Nelson, T.A. Toussoun, and P.J. Cook. (eds.). Fusarium: Disease, biology, and taxonomy. Pennsylvania State Univ. Press, University Park.

Morra, L. 1998. Potential and limits of grafting in horticulture. Informatore Agrario 54:39-42.

Nerson, H., R. Cohen, M. Edelstein, and Y. Burger. 1989. Paclobutrazol-A plant growth retardant for increasing yield and fruit quality in muskmelon. J. Amer. Soc. Hort. Sci. 114:762-766.

Pegg, G.F. 1981. Biochemistry and physiology of pathogenesis. In: M.E. Mace, A.A. Bell, and C.H. Beckman (eds.). Fungal wilt diseases of plants. Academic, New York.

Ristaino, J.B. and W. Thomas. 1997. Agriculture, methyl bromide and the ozone hole, can we fill the gap? Plant Dis. 81:964-977.

Shishido, Y., T. Yuhashi, N. Seyama, and S. Imada. 1992. Effect of leaf position and water management on translocation and distribution of $14 \mathrm{C}$ assimilates in fruiting muskmelon. J. Jpn. Soc. Hort. Sci. 60:897-903.

Traka-Mavrona, E., M. Koutsika-Sotiriou, and T. Pritsa. 2000. Response of squash (Cucurbita spp.) as rootstock for melon (Cucumis melo L.). Sci. Hort. 83:353-362. 